\title{
Synthesis of colloidal silicalite-1 at high temperatures
}

Tayyabah Butt and Lubomira Tosheva*

Division of Chemistry and Environmental Science, Manchester Metropolitan

University, Chester Street, Manchester, M1 5GD, United Kingdom

\begin{abstract}
Stable colloidal suspensions of silicalite-1 were prepared by hydrothermal treatment of clear precursor suspensions at high temperatures, $150{ }^{\circ} \mathrm{C}$ and $170{ }^{\circ} \mathrm{C}$. The precursor suspensions were pretreated prior to hydrothermal treatment. Different pretreatment procedures were applied, namely ultrasonic treatment or heating at $45-60{ }^{\circ} \mathrm{C}$, for different periods of time. In all cases, the size of the crystals decreased with increasing the time of pretreatment. The pretreatment procedure was found to influence the behavior of the tetrapropylammonium hydroxide solution used as structure-directing template during hydrothermal treatment. Colloidal stability of pretreated samples was improved compared to samples prepared by direct hydrothermal treatment.
\end{abstract}

Keywords: Silicalite-1; Colloidal; High temperature synthesis; Organic template

"Corresponding author. Tel.: +44 161274 1426; Fax: +44 1612746840

E-mail address: 1.tosheva@mmu.ac.uk (L. Tosheva) 


\section{Introduction}

Clear tetrapropylammonium (TPA) hydroxide-containing mixtures yielding colloidal silicalite-1 are probably the most-studied systems in zeolite science [1-6]. The high interest in these systems is inspired by the simplicity of the aluminum-free zeolite precursors and their homogeneity, the low synthesis temperatures employed allowing in-situ characterization by a range of advanced techniques, as well as the high reproducibility of the results. In addition to their fundamental importance, colloidal silicalite-1 crystals have been used extensively as seeds for the fabrication of supported zeolite layers and three-dimensional structures [7]. More recently, silicalite-1 seeds were employed in the revitalized seed-induced synthesis method, for preparation of nanosized ZSM-5 [8-12]. Despite the tremendous importance of systems yielding monodisperse suspensions of silicalite-1, there are technological drawbacks, such as employment of abundant amounts of expensive and toxic TPA template solutions, expensive silica sources (tetraethyl orthosilicate, TEOS), long synthesis times and low product yields, which prohibit their commercialization.

Silicalite-1 is a synthetic molecular sieve, which can only be synthesized in the presence of TPA as structure-directing agent (SDA) [13]. Monodisperse suspensions of silicalite- 1 with a size of $<100 \mathrm{~nm}$ have been prepared at temperatures below $100{ }^{\circ} \mathrm{C}$ using TPAOH in large excess. Numerous studies have looked at the mechanism of formation of silicalite- 1 and how the TPA cations interact with the silicate species during ageing and crystallization $[2,3]$. The effect of silicalite-1 precursors' aging for up to 30 days at ambient conditions has been studied by Li et al. [14]. Aging was found to shorten the induction and nucleation periods and crystallization times, as well as to result in smaller product crystals. The same group has developed a two-stage 
temperature-varying procedure, in which the precursor suspension was firstly treated at a lower temperature during the nucleation period $\left(60\right.$ or $\left.80^{\circ} \mathrm{C}\right)$ followed by a rapid change of the temperature to $100{ }^{\circ} \mathrm{C}[15]$. Ultimate crystal sizes corresponded to the crystal sizes produced at the lower synthesis temperature but yields were increased because of the higher temperature treatment. The yield of a the two-stage $60-100{ }^{\circ} \mathrm{C}$ procedure has further been improved by addition of methylene blue to the precursor suspension [16].

Temperatures higher than $100{ }^{\circ} \mathrm{C}$ have also been used to prepare nanozeolites of improved yield. Valtchev et al. have aged silicalite-1 and ZSM-5 precursor suspensions at room temperature for up to 60 days, which was followed by hydrothermal treatment at $230{ }^{\circ} \mathrm{C}$ for $2 \mathrm{~h}$ [17]. The product crystals were generally nanosized crystals with welldefined crystal facets but with broad particle size distributions. In addition, almost $100 \%$ silica conversion was achieved. Tatsumi and co-workers have pretreated silicalite-1 precursor suspensions at $80{ }^{\circ} \mathrm{C}$ for $24 \mathrm{~h}$ prior to hydrothermal treatment at $170{ }^{\circ} \mathrm{C}$ for $24 \mathrm{~h}$ to produce nanosized crystals [18]. Addition of $\mathrm{L}_{\text {-glutamic }}$ acid resulted in further decrease of the crystal size, which effect was more pronounced for more diluted solutions.

The above examples undoubtedly indicate that complete silica conversion can only be achieved at high, $>100{ }^{\circ} \mathrm{C}$, temperatures. All precursor suspensions yielding nanosized silicalite-1 contain TPAOH in large excess, imposing a major barrier to industrial applications. TPAOH is unstable at high temperatures and decomposes, resulting in brownish color of the as made silicalite-1 suspensions. Whereas there are numerous thermal analysis- studies on the decomposition of TPA cations from MFItype precursors and crystals [19-26], these studies do not account for changes in the 
state of the excess TPA cations, which are not associated with the silicate species in the system. In all these works, samples were filtered /centrifuged prior to thermal analysis, thus leaving the excess SDA in the mother liquor. Hoffman type elimination followed by $\beta$-eliminations have been proposed to be the decomposition mechanism of TPA cations from the pores of MFI-type zeolites [19-23]. The $\mathrm{TPA}^{+}$decomposition temperature has been found to strongly depend on the environment. For instance, the temperatures of max weight loss for pure $\mathrm{TPAOH}$ were $145^{\circ} \mathrm{C}$ and $240{ }^{\circ} \mathrm{C}$ compared to a single temperature of $430{ }^{\circ} \mathrm{C}$ for TPA-silicalite-1 [19]. These results suggest that the decomposition mechanism of the excess $\mathrm{TPA}^{+}$is probably similar to the decomposition mechanism of TPA cations occluded in the zeolite pores, but shifted to lower temperatures. TPA decomposition from silicalite-1 has also been found to depend on the specific conditions used during analysis, such as heating rate and gas atmosphere $[23,27]$. The objectives of the present study were to optimize the synthesis of nanosized silicalite- 1 at high, $\geq 150{ }^{\circ} \mathrm{C}$, temperatures in terms of crystal size and colloidal stability, and also to show that different synthesis procedures can influence the state of excess TPAOH molecules at the end of the high temperature hydrothermal treatment.

\section{Experimental}

Silicalite-1 clear precursor suspension was prepared from a mixture with the molar composition 9TPAOH : $25 \mathrm{SiO}_{2}: 480 \mathrm{H}_{2} \mathrm{O}$ from tetrapropylammonium hydroxide (TPAOH, 1M aqueous solution, Alfa Aesar), tetraethyl orthosilicate (98\%, Aldrich) and distilled water [28]. The mixture was vigorously stirred for $1 \mathrm{~h}$ to hydrolyze the TEOS, followed by pretreatment for different periods using different pretreatment procedures. Initial pretreatment experiments were performed in an ultrasonic bath (Sonorex TK30, $50 \mathrm{kHz}$ ) for times of up to $9 \mathrm{~h}$. No special measures were taken during the ultrasonic 
treatment to control the temperature of the ultrasonic bath, which raised to ca. $47^{\circ} \mathrm{C}$ within 1 hour. Further pretreatment experiments were performed in a water bath at 45 ${ }^{\circ} \mathrm{C}$ using similar pretreatment times. Last series of pretreatment experiments were performed in an oil bath under reflux. The pretreated synthesis solutions were transferred to PTFE-lined stainless steel autoclaves and hydrothermally treated at 150 ${ }^{\circ} \mathrm{C}$ for $19 \mathrm{~h}$, or at $170{ }^{\circ} \mathrm{C}$ for $24 \mathrm{~h}$. Reference zeolite samples were prepared similarly but without the pretreatment step. Finally, a silicalite- 1 sample was prepared at $95{ }^{\circ} \mathrm{C}$ by transferring the precursor suspension to a polypropylene reactor followed by hydrothermal treatment in a conventional oven for $48 \mathrm{~h}$. Pure TPAOH were also prepared in analogous experiments, with or without pretreatment. Some samples were crystallized in a microwave oven (Monowave 300, Anton Paar Ltd.) for $2 \mathrm{~h}$ at $150{ }^{\circ} \mathrm{C}$. After the synthesis, the samples were purified by two-times centrifugation at $6000 \mathrm{rpm}$ and redispersion in distilled water, and stored in distilled water.

The size and morphology of the samples was studied by scanning electron microscopy (SEM) using a JEOL 5600LV instrument. Droplets of the purified suspensions were dried on carbon tapes, which had been fastened to Al stubs, and coated with Au prior to analysis. Particle diameters and zeta potentials were determined by dynamic light scattering (DLS) using a Zetasizer Nano ZS instrument with a173 ${ }^{\circ}$ backscattering angle geometry. Thermogravimetric analysis (TGA) was performed with a TGA4000 instrument from Perkin Elmer. Samples were heated to $900{ }^{\circ} \mathrm{C}$ at a heating rate of $10{ }^{\circ} \mathrm{C} \mathrm{min}^{-1}$ under air.

\section{Results and discussion}

\subsection{Preliminary optimization of the pretreatment procedure}


Initial experiments were performed using an ultrasonic pretreatment for 5 and 9 h. As described in experimental, during pretreatment, the temperature of the ultrasonic bath gradually raised to ca. $47^{\circ} \mathrm{C}$. Microwave and conventional heating modes were used for the subsequent hydrothermal treatment at $150{ }^{\circ} \mathrm{C}$. A decrease in the silicalite- 1 size with an increase in the time of ultrasonic pretreatment was observed in both cases (Fig. 1). The decrease was more pronounced for the microwave synthesis (Fig. 1a-c) compared to conventional heating (Fig. 1e,f). To determine the effect of the temperature rise, experiments were performed using an ultrasonic treatment at $0{ }^{\circ} \mathrm{C}$, by adding ice to the ultrasonic bath. It was found that in this case, the ultrasonic pretreatment had no effect on the size of silicalite-1 crystals (Fig. S1), indicating that the temperature rise was the main reason for the reduced crystal sizes observed in Fig. 1. This conclusion was confirmed by performing the pretreatment in a water bath at $45^{\circ} \mathrm{C}$. A similar degree of size reduction was observed for samples pretreated for the same periods of time in ultrasonic bath and in water bath (Figs. $1 \mathrm{~b}$ and $1 \mathrm{~d}$ ). Ultrasound has been reported to increase the nucleation, particle growth and crystallization rates of silicalite1 synthesized at $75^{\circ} \mathrm{C}$ [29]. In this work, ultrasonound was applied for short times during the initial stages of nucleation, which may be the reason for its insignificant effect on the final particle size. Thus, further optimization of the pretreatment procedure was carried out by preheating the samples without applying ultrasound. Oil bath and reflux conditions were used instead of water bath pretreatment when longer $(\geq 24 \mathrm{~h})$ pretreatment times were used. First, pretreatment experiments were performed at 45, 55 and $60{ }^{\circ} \mathrm{C}$. The crystal size decreased with prolonging the pretreatment time and also with increasing the temperature (results not shown). Next, the influence of pretreatment time at $60{ }^{\circ} \mathrm{C}$ was studied. It was found that final particle sizes varied in the range 110 - 
$100 \mathrm{~nm}$ upon increasing the pretreatment time at $60^{\circ} \mathrm{C}$ between $24-48 \mathrm{~h}$, correspondingly. Samples prepared using a pretreatment for $24 \mathrm{~h}$ were then studied in detail and results will be presented in Section 3.3.

\subsection{Hydrothermal treatment of pure TPAOH solutions}

All samples after the hydrothermal treatment were milky suspensions. However, whereas the samples prepared by microwave heating and most of the samples prepared with pretreatment were whitish, the samples prepared by direct hydrothermal treatment at $150{ }^{\circ} \mathrm{C}$ and $170{ }^{\circ} \mathrm{C}$ in conventional oven were brownish. This suggested that the TPAOH decomposed at high temperatures and the decomposition was dependent on pretreatment. This effect was studied by applying different pretreatment procedures to pure $1 \mathrm{M}$ TPAOH solutions followed by hydrothermal treatment at $150{ }^{\circ} \mathrm{C}$ or $180{ }^{\circ} \mathrm{C}$ for $19 \mathrm{~h}$ (Fig. 2). The samples prepared by direct treatment were brownish but the color intensity was more pronounced for the sample prepared at $150{ }^{\circ} \mathrm{C}$ (Fig. 2a,d). The samples prepared by pretreatment in water bath for $5 \mathrm{~h}$ were also brownish but there was a clear reduction in the colorization for the sample prepared at $180{ }^{\circ} \mathrm{C}$ (Fig. $2 \mathrm{~b}, \mathrm{e}$ ). The samples prepared with ultrasonic pretreatment for $5 \mathrm{~h}$ were colorless at both temperatures (Fig. 2c,f). Another observation was that the samples prepared at $180{ }^{\circ} \mathrm{C}$ contained two immiscible liquid phases (Fig. 2d-g). These results indicated that the temperature of hydrothermal treatment and the pretreatment procedure had an effect on the decomposition products of TPAOH. Ultrasound is often used to degas liquids and remove microscopic bubbles. Vacuum filtration was applied to a TPAOH solution prior to its hydrothermal treatment at $180^{\circ} \mathrm{C}$. The resultant color of the treated solution (Fig. $2 \mathrm{~g}$ ) was similar to the color of the TPAOH solution pretreated in the ultrasonic bath (Fig. 2f). $\mathrm{pH}$ measurements further confirmed changes in the TPAOH decomposition 
products; $\mathrm{pH}$ was about $13-13.3$ for samples prepared at $150{ }^{\circ} \mathrm{C}$ and dropped to about 10.5-11.2 for samples prepared at $180{ }^{\circ} \mathrm{C}$. As mentioned in the introduction, the decomposition of TPA probably follows Hoffman type elimination followed by $\beta$ eliminations, yielding different products such as ammonia, propene, propylamine, dipropylamine, tripropylamine, etc. [19,21,23]. TPA can be recycled when silicalite-1 synthesis is performed at low temperatures. However at high temperatures, which are needed to achieve high yields, it decomposes and it is important to study the decomposition products of excess TPA in order to optimize the synthesis in terms of its greenness / recycling and gather data to assess potential commercialization.

\subsection{High temperature synthesis of colloidal silicalite-1}

Following the optimization of the pretreatment procedure, the synthesis performed after pretratement at $60{ }^{\circ} \mathrm{C}$ for $24 \mathrm{~h}$ was studied in detail. Results were also compared to a typically employed low temperature $\left(95^{\circ} \mathrm{C}\right)$ synthesis from the same precursor system. Fig. 3 shows SEM images of samples prepared without and with pretreatment at $150{ }^{\circ} \mathrm{C}$. The pretreatment procedure resulted in particles of reduced crystal sizes (Fig. 3a,b). Nevertheless, the crystals had well-defined crystal facets compared to crystals synthesized at $95^{\circ} \mathrm{C}$. The particles prepared using vacuum filtration of the pretreated precursor suspension prior to hydrothermal treatment were slightly smaller (Fig. 3b,c) and similar in size and morphology to the crystals prepared at $95{ }^{\circ} \mathrm{C}$ (Fig. 3d). The pretreatment procedure was also used for samples prepared at $170^{\circ} \mathrm{C}$ and a similar effect on the particle size was observed (Fig. 4). All samples were studied by DLS (Fig. 5). In all cases, the polydispersity indices were less than 0.1 indicating monodispersity. DLS results confirmed the SEM observations. For samples prepared at $150{ }^{\circ} \mathrm{C}$, the particle size decreased from $218 \mathrm{~nm}$ (direct synthesis) to $108 \mathrm{~nm}$ 
(pretreated) and $103 \mathrm{~nm}$ (pretreated and filtered). The size and DLS particle size distribution of the sample prepared with vacuum filtration were identical to the result for the crystals prepared at $95^{\circ} \mathrm{C}$ (Fig. 5a) and this result was reproducible. For syntheses at $170{ }^{\circ} \mathrm{C}$, the particle size decreased from $243 \mathrm{~nm}$ (direct synthesis) to 122 $\mathrm{nm}$ (pretreated) (Fig. 5b). Another observation from the DLS study was the narrower particle size distributions for samples prepared with pretreatment at both temperatures, $150{ }^{\circ} \mathrm{C}$ and $170{ }^{\circ} \mathrm{C}$ (Fig. S2). All purified samples were stored at ambient conditions in centrifuged tubes arranged vertically in a rack. A certain degree of crystal settlement was observed after three months, which was more pronounced for the samples prepared by direct hydrothermal treatment. No such sedimentation was observed for the sample prepared with vacuum filtration. The zeta potential of the samples was determined to compare the colloidal stability of the samples. The zeta potential of all pretreated samples was $<-40 \mathrm{mV}$ indicating high colloidal stability, compared to the samples prepared by direct treatment: $-21.6 \mathrm{mV}$ and $-36.2 \mathrm{mV}$ for the samples prepared at 150 ${ }^{\circ} \mathrm{C}$ and $170{ }^{\circ} \mathrm{C}$, correspondingly. The zeta potential of the sample prepared at $150{ }^{\circ} \mathrm{C}$ with pretreatment was $-41.9 \mathrm{mV}$, whereas the sample prepared with subsequent vacuum filtration had a zeta potential of $-46.7 \mathrm{mV}$, which may explain the improved colloidal stability of the latter.

The synthesis of colloidal silicalite-1 is always based on excess use of TPA. For example, in the current work, the TPA excess is more than eight times the stoichiometric amount needed for the crystallization of silicalite-1. Thermogravimetric analysis was performed to further study the role of temperature and pretreatment on the extent of template occlusion within the zeolite pores. As made suspensions were directly dried after the synthesis and the resultant glassy solids were grinded prior to TG 
analysis. Thus, these results are different from TG results reported in other works, where as made samples have been separated from the mother liquor by centrifugation prior to drying and do not contain the main fraction of the excess TPA $[18,26]$. TG curves of the samples prepared at $150{ }^{\circ} \mathrm{C}$ and $170{ }^{\circ} \mathrm{C}$ are shown in Fig. 6 . The TG result for a sample prepared in a typical low temperature $\left(95^{\circ} \mathrm{C}\right)$ synthesis is also included for a comparison. The high temperature weight loss in the range $300-350{ }^{\circ} \mathrm{C}$ corresponds to the loss of TPA from silicalite-1 pores. From Fig. 6 and the DTG curves shown in Fig. 7, it is clear that the amount of TPA occluded in the zeolite pores increased with an increase in the synthesis temperature to reach ca. $11 \mathrm{wt} . \%$ for the samples prepared at $170{ }^{\circ} \mathrm{C}$, which weight loss was close to the weight loss corresponding to purified samples (ca. 12 wt.\%). Interestingly, there were differences in the DTG peaks corresponding to the weight loss in this temperature range for the different samples (Fig. 7). These differences may be attributed to differences in crystal sizes and number of crystal defects [18]. The weight loss in the range $100-180{ }^{\circ} \mathrm{C}$ is related to loose TPA cations [26]. Again, the weight loss in this temperature range decreased with increasing the synthesis temperature (Fig. 6). The thermal stability of TPA cations depends on the interaction with the surrounding silicate network, which explains the slight shift of the DTG peaks of samples prepared at $150{ }^{\circ} \mathrm{C}$ to higher temperature compared to the sample prepared at $95^{\circ} \mathrm{C}$ (Fig. 7a) [19]. For samples prepared at $170{ }^{\circ} \mathrm{C}$, additional DTG peaks at ca. $190{ }^{\circ} \mathrm{C}$ were present (Fig. 7b), which can be attributed to the decomposition of physisorbed amines [19]. The samples prepared at $150{ }^{\circ} \mathrm{C}$ with pretreatment also showed small DTG peaks in the region $180-280{ }^{\circ} \mathrm{C}$ (Fig. 7a and Fig. S3) further confirming that pretreatment influences the TPA decomposition products.

\section{Conclusions}


Silicalite-1 suspensions were prepared at high temperatures $\left(150^{\circ} \mathrm{C}\right)$ with similar particle size distributions and colloidal stability to samples prepared at low temperatures $\left(95^{\circ} \mathrm{C}\right)$, by adjusting the crystallization conditions. Pretreatment of the precursor suspensio at $60{ }^{\circ} \mathrm{C}$ for $24 \mathrm{~h}$ followed by vacuum filtration was used to achieve the above result. The reduction of particle sizes of silicalite-1 using similar approaches has been reported in other studies. The current work, however, demonstrates that the pretreatment procedure affects the decomposition products of TPAOH used as structuredirecting template when high temperatures are employed. Although, these decomposition products are not studied in detail here, the work opens up avenues to explore this so far untouched area, namely the changes in the excess template solutions used for preparation of colloidal zeolites at high temperatures as function of crystallization conditions. The knowledge of these changes will allow to optimize syntheses in terms of yield, product characteristics and cost and provide another aspect to consider when assessing their potential commercialization.

\section{Acknowledgements}

The authors are grateful to Anton Paar Ltd. for providing the Monowave 300 microwave oven used in this work. The authors would also like to than Dr. Saeed Gulzar (MMU) for SEM images.

\section{References}

[1] C. E. A. Kirschhock, R. Ravishankar, F. Verspeurt, P. J. Grobet, P. A. Jacobs, J. A. Martens, J. Phys. Chem. B 103 (2001) 4965-4971.

[2] L. Tosheva, V. P. Valtchev, Chem. Mater. 17 (2005) 2494-2513.

[3] S. Mintova, N. H. Olson, J. Senker, T. Bein, Angew. Chem. Int. Ed. 41 (2002) 25582561. 
[4] T. M. Davis, T. O. Drews, H. Ramanan, C. He, J. S. Dong, H. Schnablegger, M. A. Katsoulakis, E. Kokkoli, A. V. McCormick, R. L. Penn, M. Tsapatsis, Nat. Mater. 5 (2006) 400-408.

[5] S. A. Pelster, R. Kalamajka, W. Schrader, F. Schüth, Angew. Chem. Int. Ed., 46 (2007) 2299-2302.

[6] L. Tosheva, B. Mihailova, L. H. Wee, B. Gasharova, K. Garbev, A. M. Doyle, Angew. Chem. Int. Ed. 47 (2008) 8650-8653.

[7] L. Tosheva, A. M. Doyle, in: V. Valtchev, S. Mintova, M. Tsapatsis (Eds.), Ordered Porous Solids Recent Advances and Prospects, Elsevier, Amsterdam, 2009, pp. 501519.

[8] G. Majano, A. Darwiche, S. Mintova, V. Valtchev, Ind. Eng. Chem. Res. 48 (2009) 7084-7091.

[9] N. Ren, Z.-J. Yang, X.-C. Lv, J. Shi, Y.-H. Zhang, Y. Tang, Micropor. Mesopor. Mater. 131 (2010) 103-114.

[10] N. Ren, J. Bronić, B. Subotić, X.-C. Lv, Z.-J. Yang, Y. Tang, Micropor. Mesopor. Mater. 139 (2011) 197-206.

[11] N. Ren, J. Bronić, B. Subotić, Y.-M. Song, X.-C. Lv, Y. Tang, Micropor. Mesopor. Mater. 147 (2012) 229-241.

[12] T. Xue, Y. M. Wang, M.-Y. He, Micropor. Mesopor. Mater. 156 (2012) 29-35.

[13] E. M. Flanigen, J. M. Bennett, R. W. Grose, J. P. Cohen, R. L. Patton, R. M. Kirchner, J. V. Smith, Nature 271 (1977) 512-516.

[14] Q. Li, B. Mihailova, D. Creaser, J. Sterte, Micropor. Mesopor. Mater. 43 (2001) 51-59.

[15] Q. Li, D. Creaser, J. Sterte, Micropor. Mesopor. Mater. 31 (1999) 141-150. 
[16] C. M. Lew, Z. Li, S. I. Zones, M. Sun, Y. Yan, Micropor. Mesopor. Mater. 105 (2007) 10-14.

[17] V. P. Valtchev, A.-C. Faust, J. Lézervant, Microporo. Mesopor. Mater. 68 (2004) 91-95.

[18] R. Watanabe, T. Yokoi, T. Tatsumi, J. Colloid Interface Sci. 356 (2011) 434441.

[19] L. M. Parker, D. M. Bibby, J. E. Patterson, Zeolites 4 (1084) 168-174.

[20] V. R. Choudhary, S. G. Pataskar, Thermochim. Acta 97 (1986) 1-10.

[21] M. Soulard, S. Bilger, H. Kessler, J. L. Guth, Zeolites 7 (1986) 463-470.

[22] M. Soulard, S. Bilger, H. Kessler, J. L. Guth, Thermochim. Acta 204 (1992) $167-178$.

[23] X. Gao, C. Y. Yeh, P. Angevine, Micropor. Mesopor. Mater. 70 (2004) 27-35.

[24] Z. Gabelica, J. B. Nagy, P. Bodart, N. Dewaele, A. Nastro, Zeolites 7 (1987) 6772.

[25] K. R. Franklin, B. M. Lowe, Thermochim. Acta 127 (1988) 319-327.

[26] B. Tokay, M. Somer, A. Erdem-Şenatalar, F. Schüth, R. W. Thompson, Micropor. Mesopor. Mater. 118 (2009) 143-151.

[27] K. H. Gilbert, R. M. Baldwin, J. D. Way, Ind. Eng. Chem. Res. 40 (2001) 48444849.

[28] A. E. Persson, B. J. Schoeman, J. Sterte, J.-E. Otterstedt, Zeolites 14 (1994) 557567.

[29] H. Gürbüz, B. Tokay, A. Erdem-Şenatalar, Ultrason. Sonochem. 19 (2012) 1108-1113. 


\section{Figure captions}

Figure 1. SEM images of silicalite-1 crystals prepared by: (a-d) microwave heating after ultrasonic treatment for (a) $0 \mathrm{~h}$; (b) $5 \mathrm{~h}$; (c) $9 \mathrm{~h}$ and (d) water-bath treatment for $5 \mathrm{~h}$; and $(e, f)$ conventional heating after ultrasonic treatment for (e) $0 \mathrm{~h}$ and (f) $5 \mathrm{~h}$.

Figure 2*. 1M TPAOH aqueous solutions after hydrothermal treatment for $19 \mathrm{~h}$ at: (a-c) $150{ }^{\circ} \mathrm{C}$ and $(\mathrm{d}-\mathrm{g}) 180^{\circ} \mathrm{C} .(\mathrm{a}, \mathrm{d})$ : direct treatment; (b, e) after pretreatment in a water bath at $45^{\circ} \mathrm{C}$ for $5 \mathrm{~h}$; (c, f) after pretreatment in an ultrasonic bath for $5 \mathrm{~h}$; and (g) direct treatment after vacuum filtration.

Figure 3. SEM images of silicalite-1 nanocrystals prepared at $150{ }^{\circ} \mathrm{C}$ (a) without , (b) with pretreatment, (c) pretreatment and filtration; and (d) by direct synthesis at $95{ }^{\circ} \mathrm{C}$.

Figure 4. SEM images of silicalite-1 nanocrystals prepared at $170{ }^{\circ} \mathrm{C}$ (a) without, and (b) with pretreatment.

Figure 5. DLS particle size distributions of silicalite-1 prepared at (a) $150{ }^{\circ} \mathrm{C}$ and (b) $170{ }^{\circ} \mathrm{C}$. D-direct synthesis, P-pretreated samples, $\mathrm{PF}$ - pretreated samples followed by vacuum filtration.

Figure 6. TG curves of silicalite-1 samples prepared by direct treatment (D), after pretreatment $(\mathrm{P})$ or after pretreatment followed by vacuum filtration $(\mathrm{PF})$, at 150 or 170 ${ }^{\circ} \mathrm{C}$. The top curve represents a typical TG curve of purified silicalite-1. The bottom TG curve corresponds to the sample prepared at $95^{\circ} \mathrm{C}$ by direct treatment. 
Figure 7. DTG curves of silicalite-1 samples prepared by direct treatment (D) or after pretreatment (P) at (a) $150{ }^{\circ} \mathrm{C}$ and (b) $170{ }^{\circ} \mathrm{C}$. Results for sample prepared at $95^{\circ} \mathrm{C}$ by direct treatment is included in (a) for comparison.

* Color reproduction on the Web is required. 
Figure 1
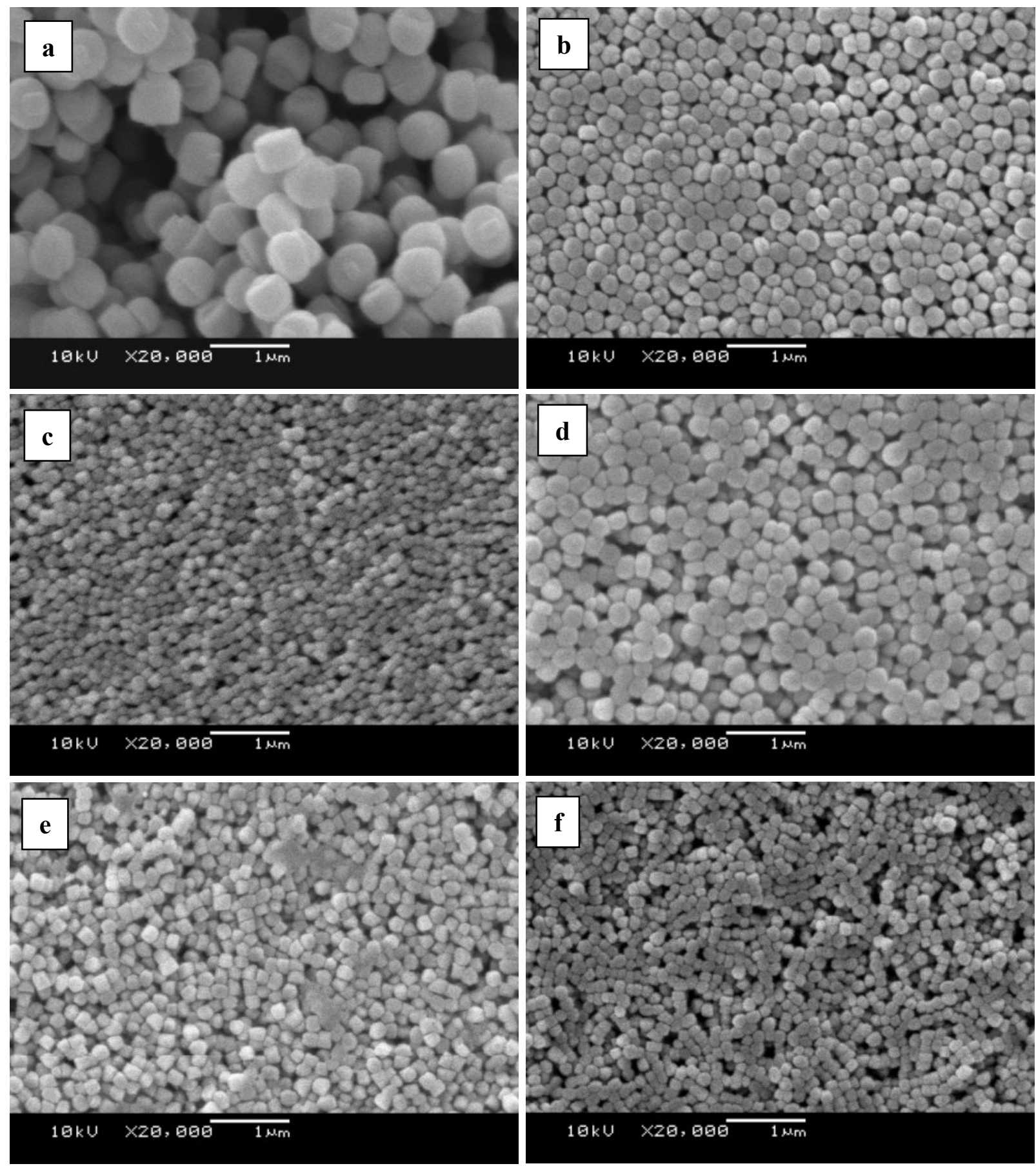
Figure 2

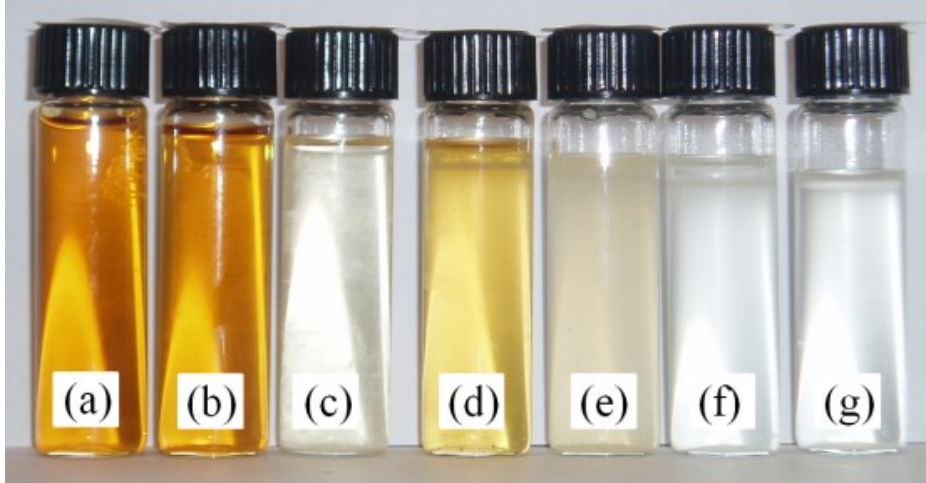


Figure 3
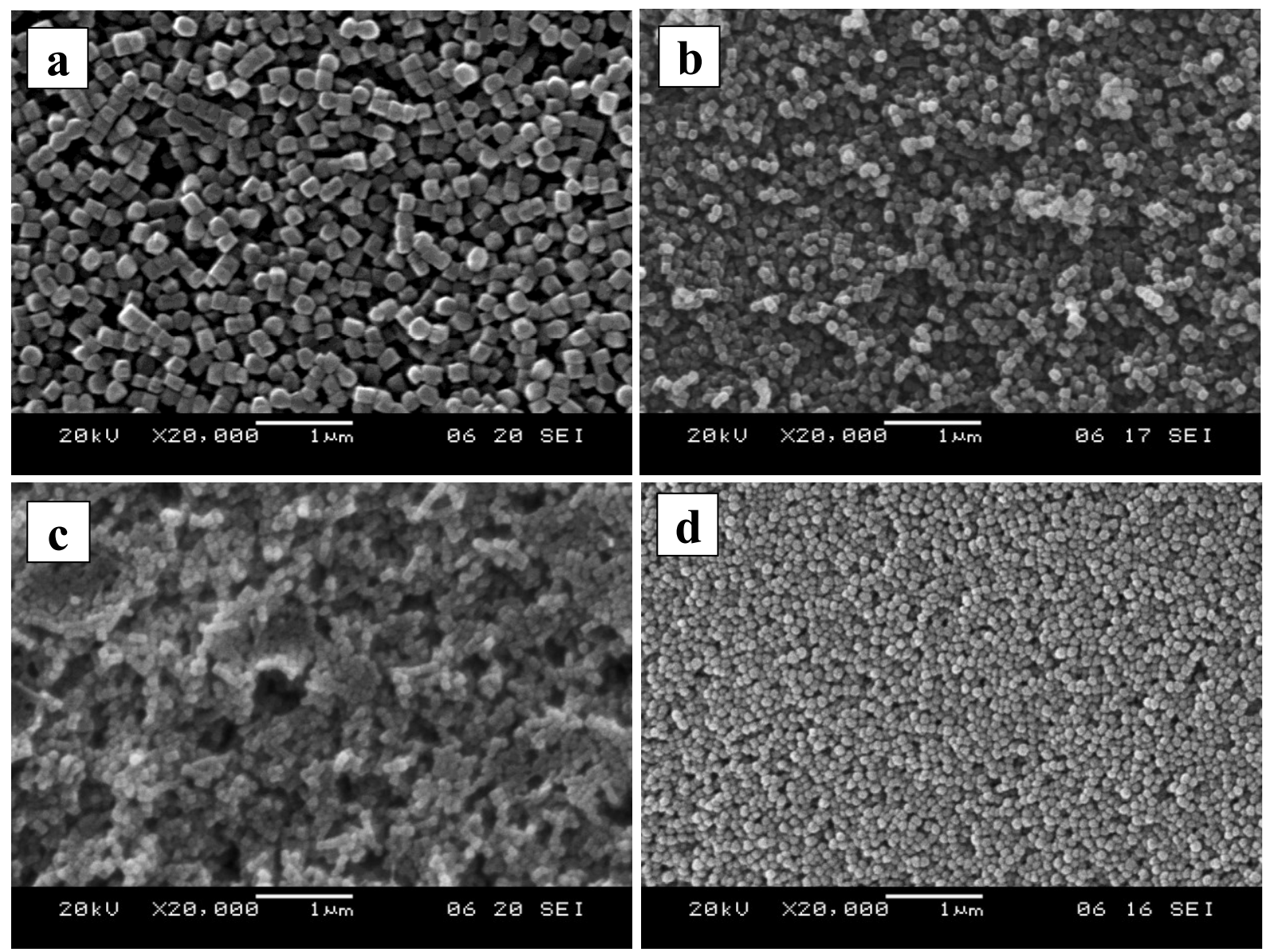
Figure 4
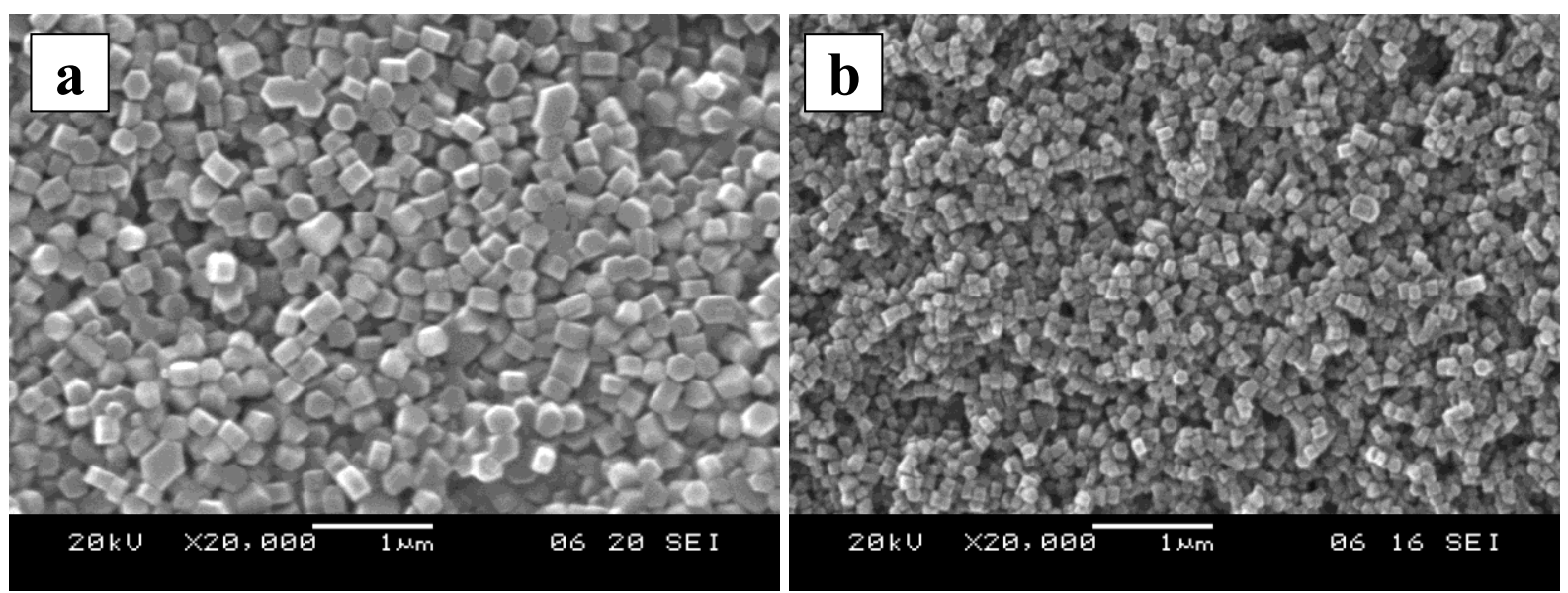
Figure 5

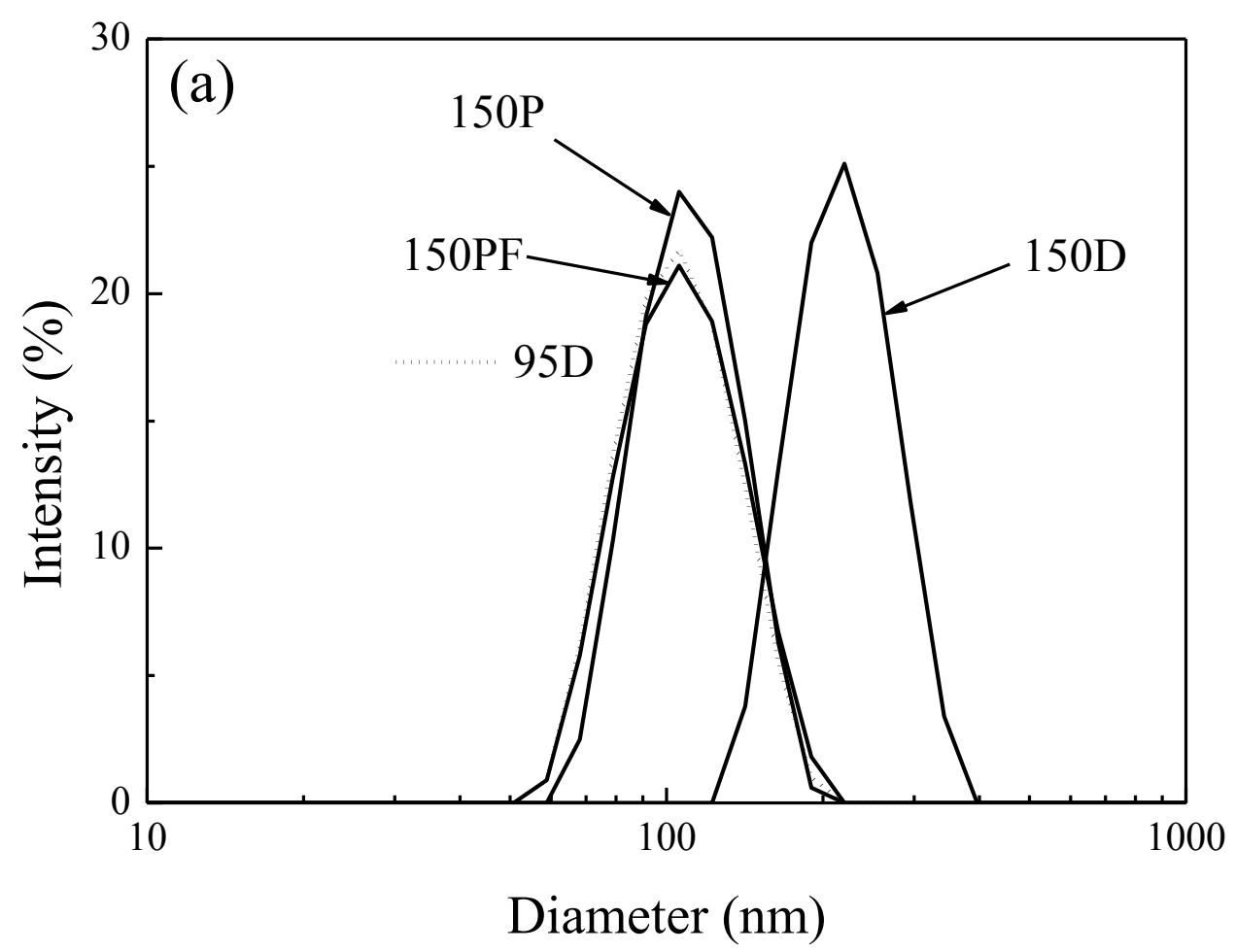


Figure 6

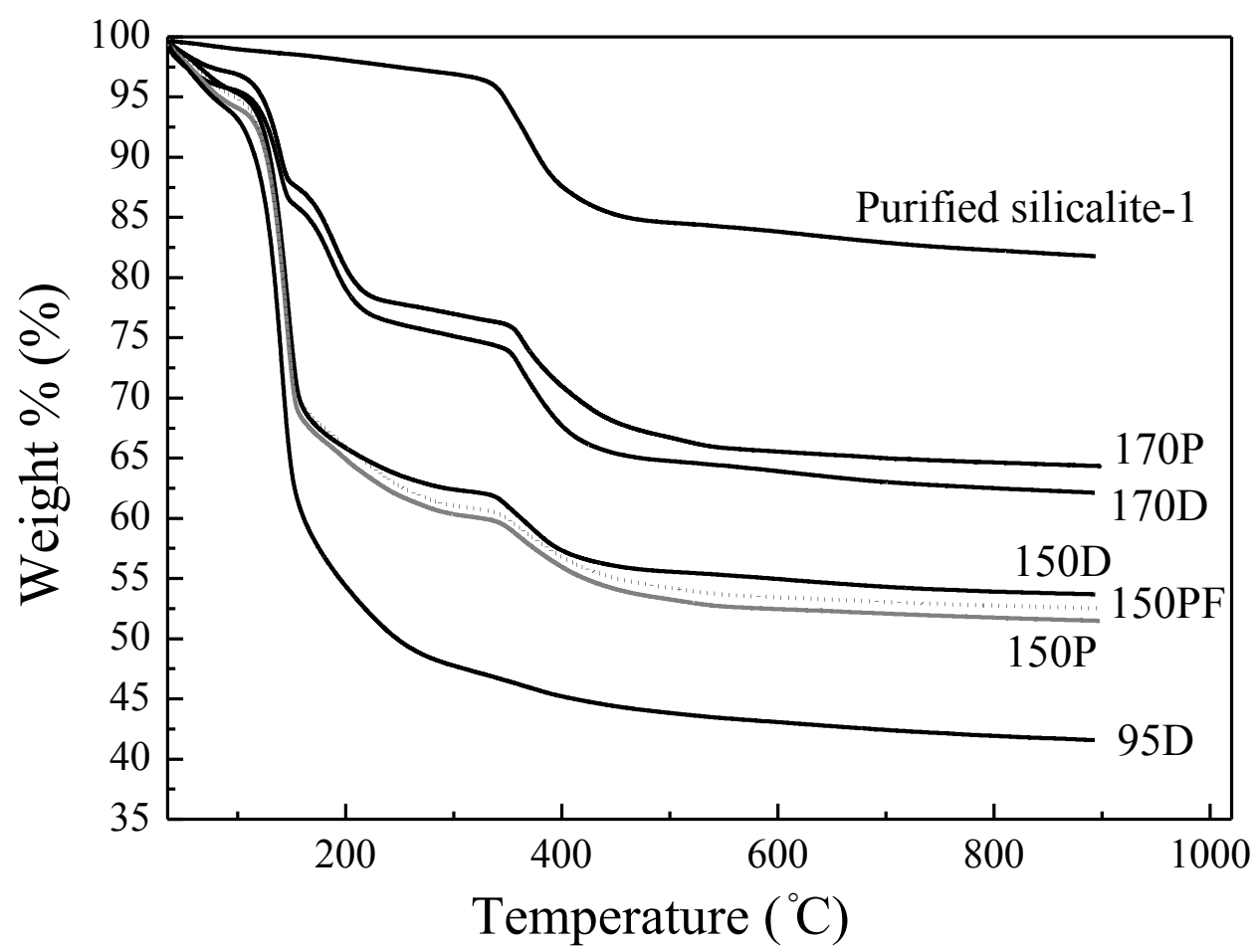


Figure 7

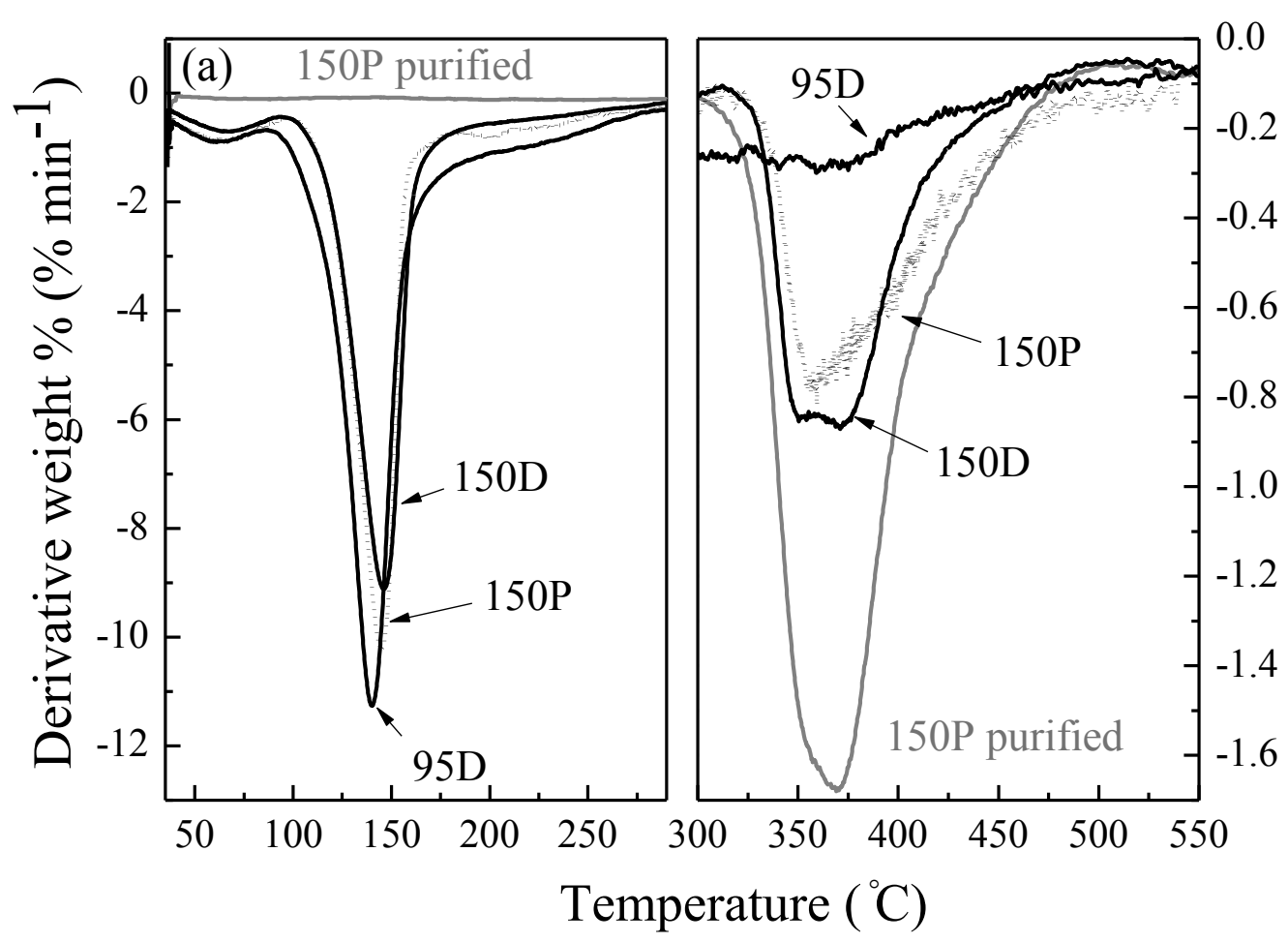

